\title{
As representações do feminino no Teatro de José de Anchieta ${ }^{1}$
}

\author{
Edélcio Mostaço ${ }^{2}$, Carla Ladeira Machado ${ }^{3}$
}

Palavras Chave: José de Anchieta, sexualidade, discurso, representação.

Resumo: Este artigo analisa as figuras femininas na dramaturgia de José de Anchieta, tendo por objeto a verificação das características associadas à sexualidade feminina e o seu papel no teatro transplantado para as Américas. Para tanto emprega alguns princípios teóricos de Michel Foucault, verificando como Anchieta caracterizou questões da sexualidade enquanto fenômeno de discurso e dispositivo disciplinar na catequese indígena.

A autoria dos escritos anchietanos é polêmica ${ }^{4}$. Sem se estender sobre esse assunto, gostaria, no entanto, para efeito do estudo aqui empreendido, de considerar a importância desses autos, quanto à legitimidade e autoridade de que estão revestidos enquanto fundadores de um discurso. Para Michel Foucault "não é preciso, pois, conceber o sujeito do enunciado como idêntico ao autor da formulação, nem substancialmente, nem funcionalmente" ${ }$, salientando que, na ordem dos discursos, o importante é determinar qual é a posição que pode e deve ocupar o enunciado, e não, exatamente, sua autoria. Parto desse pressuposto para pensar a escrita sacra que legitima a fundação católica neste território recém-descoberto.

Diante dessa perspectiva, o presente trabalho ainda tomará como apoio teórico o estudos de Brandão ${ }^{6}$ e de Carvalho ${ }^{7}$. O primeiro, ao tratar da importância da moralização de costumes na fundação do discurso católico; e segundo, ao refletir questões a respeito da mulher e o discurso de autoridade da igreja. Assim, durante a

\footnotetext{
${ }^{1}$ Projeto de pesquisa $O$ teatro nas Missões Jesuíticas - uma nova perspectiva para o teatro no Brasil Colônia, CEART/UDESC.

${ }^{2}$ Orientador, Professor do Departamento de Artes Cênicas - Centro de Artes - UDESC.

${ }^{3}$ Acadêmica do Curso de Artes Cênicas - CEART/UDESC, bolsista de iniciação científica do PIBIC/CNPq.

${ }^{4}$ Para tanto, basta verificar uma tese recente da Dra.Magda Maria Jaolino Torres aonde a autora refuta a autenticidade dos mesmos e observa as razões pelas quais tais escritos foram manipulados com propósitos os mais diversos, como por exemplo, o de corroborar com a "natureza santa" de Anchieta.

( TORRES, 2006)

${ }^{5}$ GREGOLIN, 2004.

${ }^{6}$ BRANDÃO, 2000.

${ }^{7}$ CARVALHO, 2001, p. 159-180

DAPesquisa, Florianópolis, v.2, n.4, p. 048-055, 2007.
} 
análise dos autos, busco refletir de que maneira a sexualidade feminina ${ }^{8}$ foi colocada em discurso", na medida que pretendia combater os costumes "pervertidos" e exercer sua autoridade sobre os corpos indígenas.

Do conjunto dramaturgico de Anchieta vamos examinar dois autos, o Auto da Pregação Universal e Na visitação de Santa Isabel, selecionados pelas peculiaridades com que enfocam as figuras femininas, uma vez que podem exemplificar com especial destaque o uso do discurso.

Sendo assim, a análise vai privilegiar duas representações distintas e de certa forma opostas, presentes nos autos, sendo que a primeira refere-se à mulher em sua simbologia associada à santidade, a partir das referências à Virgem Maria, em contraponto com a da mulher diabolizada, a partir das referências realizadas pelas personagens femininas ou mesmo através da personagem da Velha ${ }^{10}$.

Se considerarmos as representações femininas da Virgem Maria e da Velha como exemplos de como a conduta sexual deveria ser seguida, isso nos permite pensar no valor pedagógico a elas atribuídos no âmbito das apresentações teatrais.

É importante destacar, também, como a invisibilidade da mulher nesse contexto, das quais as duas figuras selecionadas constituem os únicos exemplos, reforça o discurso coercitivo, através da exclusão. Cabe ressaltar que naquele momento existia a iniciativa da igreja em legitimar o seu poder enquanto representante oficial religioso, e a sexualidade, como nos esclarece Foucault, foi um importante instrumento de regulação social

O presente artigo está divido em dois itens: no primeiro será exposto, brevemente, vida e obra de José de Anchieta No segundo será realizada uma análise das figuras de Maria e da Velha indígena, identificando como a sexualidade surge associada às duas figuras. No terceiro item, procurarei refletir como a sexualidade, enquanto dispositivo moral, serviu para a legitimação da Igreja como a voz da autoridade, instaurando normas e valores a serem seguidos, construindo conseqüentemente um imaginário cultural indígena.

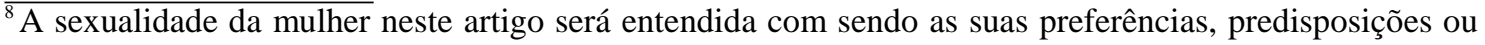
experiências sexuais.

${ }^{9}$ Para analisar a sexualidade também foram considerados os pressupostos de Michel Foucault, que entende a sexualidade como um dispositivo histórico que de acordo com as estratégias de poder e saber, incitam discursos.

${ }^{10}$ Durante a seleção e escolha das peças de José de Anchieta, foi observado que embora sejam raríssimas as personagens femininas, entre ela são a Virgem Maria em A visitação de Santa Isabel, que aparece dialogando com um romeiro; e a Velha em Na Festa de São Lourenço, que aparece e foge rapidamente quando reconhece que a figura disfarçada é o diabo. Ou ainda essas duas figuras feminina serão citadas ou referida na grande maioria dos autos de Anchieta sendo. (Ver anexo II)

DAPesquisa, Florianópolis, v.2, n.4, p. 048-055, 2007.
} 


\section{JOSÉ DE ANCHIETA, E OS COSTUMES "PERVERTIDOS"}

Jose de Anchieta (San Cristóbal de Laguna, 19 de março de 1534 - Iritiba, 9 de junho de 1597), ingressa na Companhia de Jesus, em 1551, e chega ao Brasil dois anos depois, em 13 e junho de 1553. A sua obra evangélica, e juntamente com ela a sua obra literária, é a mais significativa, escreveu uma gramática do tupi mais falado na costa do sul, poesia religiosa, épica, foi autor, também de cartas, informações, e autos religiosos.

Quanto á sua obra evangélica, no que se refere à sua atividade, o Padre Anchieta deparou-se com muitos obstáculos. O principal era o fato de os índios não conhecerem conceitos como tentação nem pecado. A catequese significava, portanto, entre outras coisas, alterar aspectos cruciais da organização familiar indígena, levando-os a abandonar seus usos e costumes "pervertidos", como a antropofagia, a poligamia, a embriaguez, etc.

A respeito das alterações de costumes Leite diz :

Destros psicólogos, aproveitaram pois os Padres esta disposição inata dos Índios, aceitando deles, a principio, o ritmo e os instrumentos, mas trocando a letra e levando-os, pouco a pouco, à prática da religião e aos costumes portugueses, que se introduziriam assim sem violências escusadas. ${ }^{11}$

Brandão, ao analisar na prosa anchietana a ambivalência missionária, constatando o duplo projeto jesuíta de missionário e colonizador, também afirma:

Combatendo os costumes contrários à religião católica, compreenderam, no entanto, que deveriam adotar em relação aos elementos externos e secundários da cultura indígena uma política de tolerância para melhor conseguirem seus objetivos. $^{12}$

Assim, utilizando a língua de origem dos indígenas, bem como a dança, a música e os cantos indígenas, Anchieta estrategicamente introduziu os elementos essenciais do seu sistema.

\footnotetext{
${ }^{11}$ LEITE, 1999, p.101

${ }^{12}$. BRANDÃO, 2000, p. 111
} 
[...] Anchieta também julgava que o problema da conversão dos nossos índios não era uma questão doutrinária, mas de moralização de costumes. Para a realização dessa tarefa seria necessário então, eliminar-lhes os "costumes inveterados" 13

Vou partir desse pressuposto para analisar, a seguir, nas peças teatrais o discurso religioso de Anchieta sobre a sexualidade, ao instituir os preceitos específicos cabíveis a um cristão. A igreja para buscar a autoridade nesses assuntos, restringindo a sexualidade ao seu domínio e controle, empregou como dispositivo importante a retórica ameaçadora, prometendo o Juízo Final a todos os que a transgredissem.

\section{TEMATIZANDO AS FIGURAS FEMININAS NOS AUTOS}

\section{A velha representando os maus costumes e o saber a ser combatido pela igreja}

A essa altura, quero retornar a um ponto que citei há pouco, o pecado original, segundo o qual não bastava apenas situar os maus costumes dos índios, era necessário que estes conhecessem a origem dos seus pecados, e a razão pela qual os desejos carnais por exemplo, eram condenados aos olhos de Deus. Tomando o primeiro ato de $A$ Pregação Universal, percebemos a introdução à origem de pecado (pecado original) e a relação que é feita aos pecados da Velha e aos dos índios.

No primeiro ato é cantado a alegoria da história do primeiro pecado, quando um moleiro (Adão), seduzido por uma mulher (Eva ou soberba) perde a sua veste de domingo (graça divina), roubada por um ladrão (o demônio).

Para a ideologia católica, Eva corresponde a figura feminina culpada pela perdição do homem. Por isso, ela se torna símbolo das impurezas e malefícios propagados pelo mundo. Eva, em contraponto a Maria, também exemplifica como deveria ser o comportamento sexual dentro dos preceitos católicos, no entanto como foi dito, a escolha da Velha deu-se em função da sua maior ocorrência nos autos, o que confere a velha um maior destaque, e talvez Anchieta objetivasse com isso sua aproximação (percebida nessa análise como representante do pecado feminino ao desejo da carne ) com a realidade indígena.

Seguindo a análise do auto, a respeito do II ato, os diabos Guaixará e Aimberé mostram o mal que fazem no Brasil. Entre os seus feitos mostrados em cena, a Velha

${ }^{13}$ Id. Ibid., p. 113 
índia parece ter uma função específica nas tramas, pois é através dela e do cauim ${ }^{14}$ que propiciam a bebedeira indígena que os diabos alcançam os seus feitos, "As velhas tentam os seus com cauim que não acaba.”.

Em função da noção de pecado original, parece que a prática sexual é um dos elementos que se atribui à velha insuflar, "Com drogas do mato e figas, cuidando de ser amadas, fazem-se belas e amigas" e que, associados aos maus costumes, exprimem a presença do demoníaco. É importante notar que a sexualidade está diretamente relacionada com a bruxaria "As velhas são más de fato: Fazendo suas magias, exaltam as fantasias .." Parece que Anchieta remonta a antigos valores onde se associa a bruxaria às mulheres, seus hábitos em fazer feitiços para conquistar homens, o seu poder de sedução através de misteriosas poções e a sua prática sexual corrompida. As velhas, desse modo, através da bruxaria, ou melhor dos seus saberes mágicos e, consequientemente, do poder que lhes conferem seus corpos, seriam os veículos para a satisfação dos desejos. È sabido que no centro da moral cristã está sua total desconfiança com relação aos prazeres carnais, que mantêm o espírito prisioneiro do corpo, impedindo-o de elevar-se na direção de Deus.

Como elemento produzido num determinado contexto histórico-social, não podemos negar que o discurso de Anchieta, principalmente pelas intenções objetivadas, apresenta fortes vinculações com as preocupações que dominavam a mentalidade da época. Com uma quase total ausência de figuras femininas nas peças, porque a referencia às velhas? Não seria pela função espiritual que elas exerciam nas tribos, e que era percebida como uma ameaça? Sabe-se que os índios atribuíam aos idosos grande respeito, sendo eles os maiores responsáveis pela continuidade da tradição. No Auto Diálogo do Pe. Pero Dias Mártir o diabo diz: "Elas não cessam seus ditos, Estão sempre discutindo:Os seus discursos malditos, Erguem calúnias e mitos, a aos seus parentes ferindo"

Gostaria de ressaltar que através das falas dos diabos ações em torno da sexualidade feminina são sempre referidas nos autos: “E agridem moças sem modos eis que aí tudo se admite" ( $N a$ festa de São Lourenço); "Mesmo alguns têm seus prazeres em as ficar espreitando" (Na Aldeia de Guaraparim); referências estas que remetem à sujeição da mulher enquanto objeto do prazer masculino. A personagem da Velha constitui, nesse sentido, uma exceção.

\footnotetext{
${ }^{14}$ Cauim: bebida fermentada grossa de cereais e frutas, mastigados pelas velhas. ANCHIETA (1977) p. 121

DAPesquisa, Florianópolis, v.2, n.4, p. 048-055, 2007.
} 


\section{A igreja e as representantes de Deus na terra}

Na maioria dos autos podemos observar como Maria é associada a imagem de interventora, mediadora e por conseguinte a grande evangelizadora. Para compreender essas representações em torno da Maria, irei apontar brevemente um fato histórico, que parece ter importante relevância. Os séculos XVI e XVII foram marcados, na esfera religiosa, por inflamados embates travados entre católicos e protestantes, que não apenas criaram fronteiras religiosas entre os estados europeus como os opôs quanto a diversas questões de dogmas, e a legitimação dos santos é um desses dogmas. A Reforma não aceitava qualquer espécie de intermediação humana na relação entre cada fiel e Deus, tal como pregavam os católicos, relações estas exercidas pelos santos e também por Maria, mãe de Jesus.

Com isso, a Companhia de Jesus, da qual José de Anchieta fez parte, foi um importante instrumento da contra-reforma, que objetivava a difusão da predica católica e a legitimação do poder político religioso católico. Nos autos de Anchieta, se considerados como veículos para propagar a ideologia católica, é constante a presença de santos e santas, e Maria nela ocupa grande destaque, como temas dos autos, e muitas vezes essas figuras aparecem nos autos como intermediadores, encarregados de proteger os espaços demarcados com as leis e o poder religioso da igreja católica, principalmente quanto às ameaças religiosas. “E por esta casa santa, que guarda sempre nas mãos, aos luteranos malsãos, com grande terror espanta, como aos Aimorés pagãos." (Na Visitação de Santa Isabel)

Voltando à figura de Maria, as representações de interventora e medianeira de Maria, associam-se a uma a imagem feminina idealizada a suscitar imitação. No caso dos indígenas tal imitação associa-se estreitamente ao esforço de mantê-los dentro da nova religião que abraçavam. Sua castidade, sempre associada a adjetivos como bela e formosa, parece ser o elemento fundamental que a diferencia das demais figuras femininas, conferindo-lhe a mais fundamental das virtudes para suscitar normas em relação ao corpo e ao desejo.

Ao discutir a respeito da constituição da "Igreja doméstica", Carvalho faz uma interessante comparação: 
A Igreja também identifica-se com Maria; ela é a mãe que zela por seus filhos na terra e também mestra, esposa de Cristo e mediadora sem a qual não havia possibilidade de acesso ao Pai. ${ }^{15}$

Verifica-se, portanto, que estamos diante de uma realidade maior, mais ampla do que a religiosa, que é a sociedade patriarcal, que reservava à mulher a condição de sujeição, no âmbito da Colônia

\section{A SEXUALIDADE COLOCADA EM DISCUSSÃO}

Ao analisarmos a figuras da Velha e de Maria (ainda que não tenham uma relação direta com a ação dramática) verificamos que suas caracterizações instituem dois paradigmas:

O primeiro deles através de adjetivos empregados - Bela/ Feia. Semanticamente esses adjetivos acumulam informações que tanto as descrevem quanto expressam um julgamento. São, portanto, um julgamento de valor, sendo a velha índia associada à negatividade e Maria à positividade.

O segundo aparece constituído pelos substantivos: a Velha representando os gentios e Maria, o cristianismo . Esses substantivos, da mesma forma, expressam julgamentos de valor.

Ao identificarmos nessa construção discursiva tanto uma designação quanto uma valoração, percebemos nessas representações elementos poderosos de exemplificação a serem instituídos através da prática teatral.

Temos, portanto, modelos de comportamentos sexuais apresentados aos indígenas no século XVI, pautados a partir de uma autoridade - a Igreja - como detentora de saber e de verdade a respeito das condutas humanas, a constituição de sujeitos aderidos à uma determinada ordem.

Assim, a proposta de refletir a partir um referencial foucaultiano, diz respeito ao quanto estas alusões teóricas têm ampliado a compreensão dos processos de subjetivação e, portanto, de constituição das identidades. Para se analisar o fenômeno da construção da identidade indigena através do teatro jesuíta no século XVI torna-se importante, nesse caso, levar-se em consideração a rede de formações discursivas que a ele está associada, mesmo quando se faz um recorte minimo como o aqui apresentado.

${ }^{15}$ CARVALHO, 2001, p. 159-180. 
Foi possível, portanto, através dessa breve analise, identificar como tais relações discursivas apoiavam-se num saber específico, no conjunto doutrinal e teológico erigido para garantir a existência da igreja enquanto instituição, na qual o teatro ocupou relevante papel. Como, através dele, os significados associados à sexualidade foram manejados e produzidos, com inevitáveis implicações que reverberam até os dias de hoje.

\section{BIBLIOGRAFIA}

ANCHIETA, Joseph de. Teatro de Anchieta. São Paulo: Loyola, Originais acompanhados de tradução versificada, introdução e notas pelo P. Armando Cardoso S. J. Obras Completas: $3^{\circ}$ volume. Edições Loyola: São Paulo, 1977.

BRANDÃO, Helena H. Nagamine. Catequese e colonização no discurso jesuítico. In: Barros. D.L.P (org.) Os discursos do descobrimento. 500 e mais anos de discursos. São Paulo: EDUSP, 2000.

CARVALHO, Maristela Moreira de. Sexualidade, controle e constituição de sujeitos: a voz da oficialidade da Igreja Católica (1960-1980). Revista Esboços - Revista do Programa de Pós- Graduação em História da UFSC, Chapecó, v. v. 7, n. 9, p. 159-180, 2001.

GREGOLIN, Maria do Rosário Valencise. O enunciado e o arquivo: Foucault (entre)vistas. In: $O$ enunciado e os Domínios da Linguagem: Discurso, poder, subjetividade. p. 28

LEITE, Serafim. História da Companhia de Jesus no Brasil. Tomo II. Livro I. Belo Horizonte: Editora Itatiaia, 1999. p.101

TORRES, D.ra Magda Maria Jaolino Torres, As práticas discursivas da Cia. De Jesus e a emergência do "Teatro Jesuítico da Missão" do Brasil no Século XVI. Tese em História. UnB: 2006. 